\title{
Drug Utilization Evaluation of Methotrexate in Psoriasis in a Tertiary Care Teaching Hospital
}

\author{
Vijeesh Tholur Subrahmanian', Kannan Gopal², Murugan Sundaram³ ${ }^{3}$ Purnima Ashok', Satya Sai \\ Minnikanti Venkata ${ }^{1}$
}

1'Department of Pharmacy Practice, KLE University's College of Pharmacy, Bengaluru-10, INDIA.

${ }^{2}$ Department of Pharmacy Practice, Saastra College of Pharmaceutical Education \& Research, Nellore-311, INDIA.

${ }^{3}$ Department of Dermatology, Sri Ramachandra University, Chennai-116, INDIA.

\begin{abstract}
Background: Psoriasis is a common inflammatory skin condition which can have profound impact on patient's quality of life. Moreover, in pharmacotherapy of psoriasis Methotrexate was the first effective systemic drug for psoriasis and remains in clinical use today. The objective of the study was to evaluate the utilization of methotrexate in psoriasis by assessing prescribing pattern, safety, efficacy and its rational use. Methods: It is a prospective, descriptive study conducted for a period of six months in subjects of either sex aged not more than 60years having psoriasis. Methotrexate was initiated in a single weekly intramuscular or oral dose of 2.5$5 \mathrm{mg}$ (maximum $30 \mathrm{mg}$ ). The treatment response was evaluated using Psoriasis Area and Severity Index in all patients at the baseline and then every month till the remission phase of the disease. Results: After treatment with methotrexate 5-15 mg, significant reduction in psoriasis score were recorded when compared to baseline therapy and also there were no significant side effects observed in the psoriatic patients. Conclusion: Use of methotrexate in the treatment of psoriasis in this study population was found to be safe and effective. Significant Psoriasis Area and Severity Index score reduction was observed during each month of therapy.
\end{abstract}

Key words: Methotrexate, Psoriasis, Psoriasis Area and Severity Index, Drug interaction.

\section{INTRODUCTION}

Psoriasis is a systemic, immunological, genetic disease manifesting in the skin and or joints with unknown etiology. Most people with psoriasis have thick, red skin with flaky, silver white patches called scales. Because of its systemic nature, patients exhibit a broad spectrum of symptoms that vary in severity and is determined by measuring the percentage of body surface area (BSA) affected. Mild psoriasis affects up to $3 \%$ of the body, moderate psoriasis affects $3 \%$ to $10 \%$ of the body's surface and severe psoriasis affects $>10 \%$ of the body. ${ }^{1}$ Occurrence of psoriasis varies from $0.1 \%$ to $0.3 \%$ in different parts of the World. It can appear at birth as well as in very old age with almost equal frequency in either sex, but slightly higher prevalence noticed in males. ${ }^{2}$ Clinically there are different types of psoriasis like plaque psoriasis, nail psoria- sis, guttate psoriasis, scalp psoriasis, inverse psoriasis, pustular psoriasis and palmoplantar pustules psoriasis. ${ }^{3,4}$

Diagnosis of psoriasis is based on clinical assessment including disease onset and symptom presentation as well as medical and life style history. Possible differential diagnosis needs to be excluded. ${ }^{5}$ The Psoriasis Area and Severity Index (PASI) score is a quantitative assessment tool to evaluate disease severity, which measures the severity of psoriatic lesions based on the extent of skin involvement and plaque appearance. ${ }^{6,7}$ To calculate PASI score, health care professionals will evaluate the level of redness, thickness and scaling of plaques. ${ }^{7}$ According to recent guidelines of American Academy of Dermatology, moderate to severe disease is defined as a PASI score $>10 .^{8}$

Methotrexate (MTX) has been in use in dermatology for more than 50 years, but it was
DOI: 10.5530/ijopp.9.4.4

Address for correspondence:

Mr.Vijeesh Tholur Subrahmanian,

Department of Pharmacy Practice,

KLE University's College of Pharmacy,

Bengaluru, Karnataka.

Phone no: 7411697720

E-mail: tholur.vijeesh@gmail. com

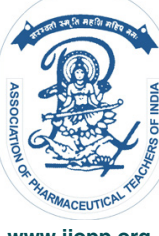

www.ijopp.org 
approved in 1972, by the US Food and Drug administration for this indication. It can be administered orally, subcutaneously or intramuscularly. ${ }^{5}$ The American Academy of Dermatology and the British Association of Dermatology have recommended a starting dose of 2.5 to $5.0 \mathrm{mg}$ per week with a gradual increase up to clinical response or maximum dose of $30 \mathrm{mg}$ per week. ${ }^{8}$ Approximately 30 to $90 \%$ of the patients will be affected by some type of MTX toxicity. There are different types of toxicities which include gastrointestinal toxicities, hepatotoxicity, hematological toxicity, pulmonary toxicity and neurological toxicity in which hepatotoxicity is the most frequent limitation of MTX treatment in psoriasis. Folic acid supplementation reduces hematologi$\mathrm{cal}$, gastrointestinal and hepatotoxic side effects without decreasing the efficacy. ${ }^{9}$

\section{Drug Utilization Review}

As per WHO, drug utilization is defined as " marketing, distribution, prescription, and use of drugs in society, with special emphasis on the resulting medical, social, and economic consequences. ${ }^{10}$ Use of prospective review, based upon complete drug and medical history obtained from an interview and from historical records, permits the practitioner to evaluate the patients pre-existing therapy on a retrospective basis, and then to prevent interactions by disallowing certain drugs for a patient on the basis of a pre-existing review and by protocols already developed. ${ }^{10}$

This study was conducted in order to evaluate the utilization of MTX in psoriasis and to ensure the safety, effectiveness and rational use by providing information to health care providers related to monitoring guidelines and drug interactions and also promoting patient adherence by effective counseling.

\section{METHODOLOGY}

\section{Study design}

It was a prospective, descriptive study where a detailed patient data collection form was specifically designed to document patient demographics, chief complaints, past medical and medication history, family history, laboratory values, provisional diagnosis and medication profile. Pre-treatment assessment of all patients included full blood count, renal profile and liver enzymes. MTX was initiated in a single weekly intramuscular or oral dose of 2.5 to $5 \mathrm{mg}$ (maximum dose $30 \mathrm{mg}$ ). It was continued until there was clinical improvement of the skin lesion and then tapped to the lowest possible maintenance dose. In addition, folic acid $5 \mathrm{mg}$ once daily was prescribed on the days when MTX was not prescribed to reduce the possible side effects of MTX. Patient edu- cational leaflets are prepared in English and Tamil and distributed to the patients included in the study along with the counseling. The study was approved by faculty of Pharmacy Research and Ethics Committee, Sri Ramachandra University, Chennai (REC-FOP/M.PHARM (PP)/2012/07).

\section{Study site:}

The study was conducted in the out-patient Department of Dermatology in a tertiary care teaching hospital, Chennai, Tamil Nadu, India.

\section{Study period:}

The study was conducted for the period of six months from July to December 2012.

\section{Study criteria}

\section{Inclusion criteria}

Subjects of either sex between 31-60 years age, having psoriasis.

Subjects who are prescribed MTX either orally or systemically.

\section{Exclusion criteria}

Patients with impaired renal function/ pre-existing renal disease and uncontrolled hypertension.

Patients on concomitant use of hepatotoxic and nephrotoxic drugs for any other disease.

Pregnant and breast feeding patients.

Patients having excessive alcohol consumption.

\section{Assessment}

\section{Efficacy:}

The treatment response was evaluated using PASI score in all patients at the baseline and then every month till the remission phase of the disease. The severity of erythema, scaling and thickness was recorded on a scale of 0 to 4 as,

0-None, 1-Mild, 2-Moderate, 3-Severe, 4- Very severe. The formula for calculating PASI score is as follows:

PASI score $=0.2(E h+I h+D h) x A h+0.2(E u+I u+D u) x$ $A u+0.3(E t+I t+D t) \times A t+0.4(E l+I l+D l) \times A l$

Where, E- Erythema, I- Induration, D- Desquamation, Ah-area of head involved in psoriasis , Au - area of upper limb involved in psoriasis, At - area of trunk involved in psoriasis, $\mathrm{Al}$ - area of lower limb involved in psoriasis, Calculation of the area involved by psoriasis as follows:

$1=$ less than $10 \%$

$2=10-29 \%$

$3=30-49 \%$

Indian Journal of Pharmacy Practice, Vol 9, Issue 4, Oct-Dec, 2016 
$4=50-69 \%$

$5=70-89 \%$

$6=90 \%$ or more

The grouping of the patients was done depending on the PASI score:

PASI $<10$ suggests mild to moderate psoriasis

PASI between 10-20 suggests moderate to severe psoriasis

PASI $>20$ suggests severe psoriasis

\section{Safety:}

To determine the safety of MTX, complete blood count, fasting blood sugar, liver function tests, renal profile were monitored regularly. Blood counts and liver enzymes were monitored during follow up, initially every week and then every two to six weeks.

\section{Statistical analysis:}

The collected data were compiled and processed using Microsoft Excel 2007. Statistical analysis was carried out by Graph pad prism version 5.0. Data were represented as mean \pm SEM.

\section{RESULTS}

This prospective study involved 46 patients. Among the patients $28(61 \%)$ were male and $18(39 \%)$ were female. Most of them were between the age of 31-60 years. Among the study population involved, 33(71.73\%) patients had psoriasis vulgaris and $13(28.26 \%)$ had

\begin{tabular}{|c|c|c|c|}
\hline PASI score & $\begin{array}{l}\text { Severity of } \\
\text { psoriasis }\end{array}$ & Frequency & Percentage \\
\hline PASI $<10$ & Mild to moderate & 0 & 0 \\
\hline PASI 10-20 & Moderate to severe & 30 & $65.21 \%$ \\
\hline PASI > 20 & Severe & 16 & $34.78 \%$ \\
\hline
\end{tabular}

\begin{tabular}{lcccc} 
Table 2: Dose distribution of MTX in patients \\
$\begin{array}{cccc}\text { Phases of } \\
\text { therapy }\end{array}$ & \multicolumn{5}{c}{ Dose of Methotrexate } \\
\cline { 2 - 5 } & $\mathbf{5 ~} \mathbf{7 . 5} \mathbf{~ m g}$ & $\mathbf{1 0 ~} \mathbf{~ m g}$ & $\mathbf{1 5} \mathbf{~ m g}$ \\
\hline Baseline & 46 & 0 & 0 & 0 \\
1st month & 26 & 6 & 9 & 5 \\
2nd month & 22 & 6 & 12 & 6 \\
3rd month & 22 & 6 & 12 & 6 \\
4th month & 22 & 6 & 12 & 6 \\
5th month & 22 & 6 & 12 & 6 \\
\hline
\end{tabular}

palmoplantar psoriasis respectively. According to the PASI score, patients with moderate to severe psoriasis were highest which accounts for $65.21 \%$ followed by patients with severe psoriasis (Table 1). Details of MTX dose in study population which shows the dose distribution of MTX in patients in every month as shown in Table 2. During the baseline therapy, all 46 patients were started MTX with a dose of $5 \mathrm{mg} /$ week. In the first month of treatment with methotrexate 26 patients were continued with $5 \mathrm{mg}$ MTX. Since 20 patients showed poor clinical response their dose was increased as 6 were prescribed with $7.5 \mathrm{mg}$, 9 were prescribed $10 \mathrm{mg}$ and 5 were prescribed with $15 \mathrm{mg}$. In the second month 3 patients dose were increased from $5 \mathrm{mg}$ to $10 \mathrm{mg}$ and one patient's dose was increased from $5 \mathrm{mg}$ to $15 \mathrm{mg}$ MTX because of poor outcome.

PASI score reduction in each dosage group: Patients are categorized into 4 groups based on the prescribed MTX dose. Mean PASI score of each group in every month is as shown in Figure. 1.

\section{PASI score assessment}

The mean PASI score was computed in the study population on monthly basis that is from first month to six months after MTX therapy initiation as shown in Figure 2. PASI score at baseline was $14.90 \pm 1.100$ for psoriasis patients. PASI score at the first, second, third, fourth and fifth months was $13.70 \pm 0.500,12.40 \pm 0.400$, $11.00 \pm 0.200,9.50 \pm 0.300$ and $8.00 \pm 0.200$ respectively. The improvement in PASI score observed in patient taking MTX was statistically significant $(\mathrm{P}<0.05)$ as shown in the Table 3.

Efficacy of methotrexate as assessed by PASI score: PASI 50 and PASI 75 are internationally most important parameters of assessment of severity of psoriasis. Clinical responses are categorized into 3 groups based on the PASI response. 15 patients achieved PASI response below PASI 50; 27 patients achieved PASI response between PASI 50-75 and 4 patients achieved PASI response above PASI 75 as shown in Table 4. This reduction in PASI scores proves the efficacy of MTX in subsiding severity of psoriasis.

\section{DISCUSSION}

Psoriasis is rarely a life threatening disease. It can cause significant morbidity, disruption in patient's life and treatment is also expensive. Patients with moderate to severe disease may require systemic therapy. MTX is a highly effective drug in the treatment of severe psoriasis. It is a folic acid antagonist which exerts antimitotic action on the epidermis by inhibiting DNA synthesis. 
In this study out of 46, patients $28(61 \%)$ were male and $18(39 \%)$ were female. Sex ratio in this study revealed that there was a strong preponderance of male patients. This sex distribution shows the similarity with the findings of other author. ${ }^{11}$ The age distribution in this study showed, patients with age group of 31-60 years were

\begin{tabular}{cc}
$\begin{array}{l}\text { Table 3: Evaluation of outcome of psoriatic patients } \\
\text { month wise using PASI Score }\end{array}$ \\
\hline $\begin{array}{c}\text { PASI score } \\
\text { (month wise) }\end{array}$ & mean \pm SEM \\
\hline Baseline & $14.90 \pm 1.100$ \\
$1^{\text {st }}$ month & $13.70 \pm 0.500^{\text {ns }}$ \\
$2^{\text {nd }}$ month & $12.40 \pm 0.400^{\text {ns }}$ \\
$3^{\text {rd }}$ month & $11.00 \pm 0.200^{* *}$ \\
$4^{\text {th }}$ month & $9.50 \pm 0.300^{* *}$ \\
$5^{\text {th }}$ month & $8.00 \pm 0.200^{\text {*** }}$ \\
\hline
\end{tabular}

Values are expressed as mean \pm SEM, $n=46{ }^{* * *} p<0.001,{ }^{* *} p<0.01$ and ${ }^{*} p<0.05$ when compared to normal control group

Table 4: Efficacy of methotrexate as assessed by PASI score

\begin{tabular}{cccc} 
S.NO & $\begin{array}{c}\text { PASI score } \\
\text { reduction range }\end{array}$ & $\begin{array}{c}\text { No. of } \\
\text { patients }\end{array}$ & $\begin{array}{c}\text { Percentage } \\
\text { (\%) }\end{array}$ \\
\hline 1. & < PASI 50 & 15 & $32.60 \%$ \\
2. & PASI $50-75$ & 27 & $58.70 \%$ \\
3. & $>$ PASI 75 & 4 & $8.7 \%$ \\
\hline
\end{tabular}

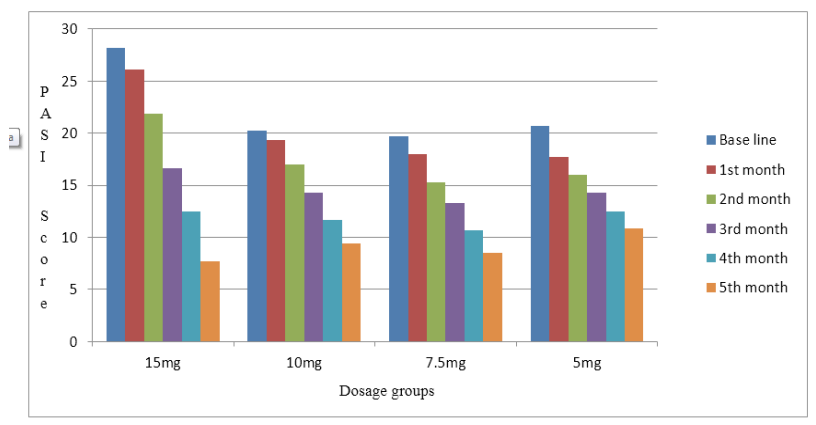

Figure 1: PASI score reduction in each dosage group

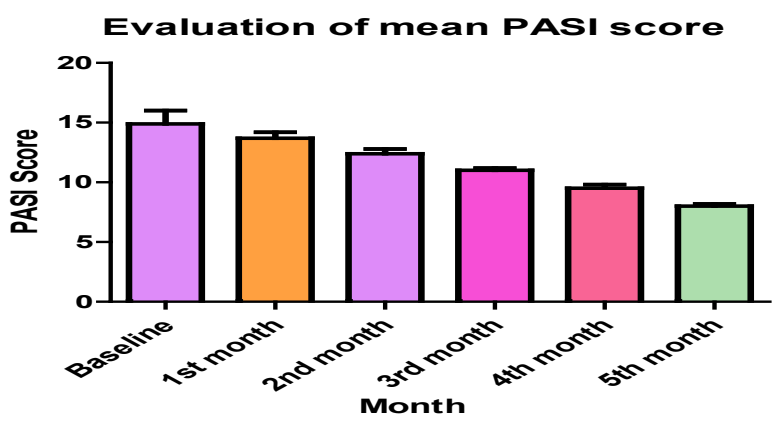

Figure 2: Evaluation of mean PASI score of psoriatic patients month wise using PASI score more prone to develop psoriasis which was similar to other study. ${ }^{12}$ The American Academy of Dermatology and the British Association of Dermatology have recommended a starting dose of 2.5 to $5.0 \mathrm{mg}$ per week with gradual increase upto clinical response or maximum dose of $30 \mathrm{mg}$ per week. In this study, dose distribution of MTX is as per the guidelines. In this study, PASI score was adopted on monthly basis to check the efficacy of MTX therapy. Reduction in PASI score revealed the decrease in severity of disease and proves the effectiveness of the treatment. PASI 50 and PASI 75 are the most important parameters employed globally for assessment of the efficacy of therapy with respect to the severity of psoriasis. PASI 75 is defined as reduction from baseline to PASI score $>75 \%$ and PASI 50 reveals reduction in the severity by $50 \%$. In the current study PASI 75 was achieved by $8.70 \%$ and PASI 50 was achieved by $58.70 \%$ of patients respectively.

There were no moderate and severe adverse effects reported by the patients. Also there was no significant drug interactions seen in medication profile. In this study, least number of adverse reactions are reported comparing with various researches ${ }^{11,13,14}$ where more side effects are reported due to high drug dose used. Since there is a recommendation that patients on MTX therapy should receive supplemental folic acid $5 \mathrm{mg} /$ day except on the day of MTX dosing to avoid gastrointestinal side effects, ${ }^{15}$ this study also supports the above findings.

\section{CONCLUSION}

Use of MTX in the treatment of psoriasis in this study population was found to be safe and effective. Significant PASI score reduction was observed during each month of therapy. There were no significant side effects observed in the psoriatic patients. Proper patient selection, counseling and appropriate monitoring is crucial to minimize the toxic effects of MTX. This study supports the use of MTX in psoriasis with minimal toxic effects.

\section{ACKNOWLEDGEMENT}

Authors acknowledge to KLE University's College of Pharmacy, Bengaluru and Sri Ramachandra University, Chennai for providing infrastructural support and also would like to thank Yuvraj Singh Surana (Research Scholar) for providing valuable support.

\section{REFERENCES}

1. Wolverton SE. Comprehensive dermatologic drug therapy. $2^{\text {nd }}$ edition. US: Elsevier Health Sciences US;2007.

Indian Journal of Pharmacy Practice, Vol 9, Issue 4, Oct-Dec, 2016 
2. Haldiman K. An overview of psoriasis: the etiology, common triggers, and current treatment options 2012: 1-12.

3. Klaus W. Fitzpatrick's dermatology in general medicine. $7^{\text {th }}$ edition. McGraw-Hill Professional;2006.

4. National psoriasis foundation. Retrieved Nov. 2011. (www.psoriasis.org.)

5. Sarah S,Tim OB, Lei MY, Prince HM, Christopher JM. The use of methotrexate in dermatology: a review. Australas J Dermatol. 2012; 53(1): 1-18.

6. Feldman SR, Kruger GG. Psoriasis assessment tools in clinical trials. BMJ 2006; 64:65-8.

7. Chládek J, Simkova $M$, Noiekova $M$, et al. Pharmacokinetics and Pharmacodynamics of low-dose methotrexate in the treatment of psoriasis. $\mathrm{Br}$. J. Clin. Pharmacol. 2002; 54(2): 147-156.

8. American academy of dermatology. Retrieved Nov.2011. (www.aad.org/skinconditions/dermatology-a-to-z/psoriasis.)

9. Al-Dabagh A, Davis SA, Kinney MA, Huang K, Feldman SR. The effect of folate supplementation on methotrexate efficacy and toxicity in psoriasis patients and folic acid by dermatologists in the USA. Am J Clin Dermatol. 2013;14(3):15561

10. Truterl. A review of drug utilization studies and methodologies. JJPS 2008; 1(2): 91-104

11. Karn D, Amatya A, Khatri R. Comparative study of methotrexate and cyclosporine in the treatment of psoriasis. NJDVL. 2010; 9(1): 15-21.

12. Chong Y T, Wong S M, Thevarajah S, Baba R. Methotrexate toxicity presenting as ulcerated psoriatic plaques. Australas J Dermatol. 2012; 53(1): 81-83.

13. Saurat $\mathrm{H} \mathrm{J}$ et al. Efficacy and safety results from randomized controlled comparative study of adalimumab vs. methotrexatre vs. placebo in patients with psoriasis(CHAMPION). Br J Dermatol. 2007; 158(3): 558-66.

14. Neerja P, Mahajan B B, Sandhu S K. Clinical evaluation of different therapeutics modalities in psoriasis by PASI score. Our Dermatol online. 2013; 4(1): 16-22.

15. Masuria B L, Mittal A, Gupta L K, Sharma M, Bansal N. Methotrexate: Side effects and role of folic acid supplementation in psoriasis. Indian J Dermatol Venerol Leprol. 1997; 63(4): 219-22. 